\title{
QUEEN'S
UNIVERSITY
BELFAST
}

\section{"The world would just fall apart if there's no respect at all": Children's understandings of respect for diversity in a post-conflict society}

Burns, S., Lyons, E., \& Niens, U. (2016). "The world would just fall apart if there's no respect at all”: Children's understandings of respect for diversity in a post-conflict society. Journal of Peace Education.

https://doi.org/10.1080/17400201.2016.1269313

Published in:

Journal of Peace Education

Document Version:

Peer reviewed version

Queen's University Belfast - Research Portal:

Link to publication record in Queen's University Belfast Research Portal

Publisher rights

(c) 2016 Taylor \& Francis Ltd. This is an Accepted Manuscript of an article published by Taylor \& Francis in Journal of Peace Education on 25 Dec 2016, available online: http://www.tandfonline.com/doi/full/10.1080/17400201.2016.1269313

\section{General rights}

Copyright for the publications made accessible via the Queen's University Belfast Research Portal is retained by the author(s) and / or other copyright owners and it is a condition of accessing these publications that users recognise and abide by the legal requirements associated with these rights.

Take down policy

The Research Portal is Queen's institutional repository that provides access to Queen's research output. Every effort has been made to ensure that content in the Research Portal does not infringe any person's rights, or applicable UK laws. If you discover content in the Research Portal that you believe breaches copyright or violates any law, please contact openaccess@qub.ac.uk. 


\section{“The world would just fall apart if there's no respect at all”: Children's understandings of respect for diversity in a post-conflict society}

*Stephanie Burns ${ }^{\mathrm{a}}$, Evanthia Lyons ${ }^{\mathrm{b}}$, and Ulrike Niens ${ }^{\mathrm{c}}$

${ }^{a}$ Queen's University Belfast; ${ }^{b}$ Kingston University London; ${ }^{c}$ Self-employed

\section{Author Note}

Author affiliations at the time of study were: Stephanie Burns, School of Psychology, Queen’s University Belfast; Evanthia Lyons, School of Psychology, Queen’s University Belfast; Ulrike Niens, School of Education, Queen’s University Belfast.

Subsequent to the study, author affiliations have changed to: Stephanie Burns, School of Social Sciences, Education and Social Work, Queen’s University Belfast; Evanthia Lyons, School of Social and Behavioural Sciences, Kingston University London; Ulrike Niens, selfemployed, Frankfurt, Germany.

*Correspondence concerning this article should be addressed to: Stephanie Burns, School of Social Sciences, Education and Social Work, Queen’s University Belfast, BT7 1HL, Northern Ireland. Email: stephanie.burns@qub.ac.uk. 


\title{
“The world would just fall apart if there's no respect at all”: Children's understandings of respect for diversity in a post-conflict society
}

\author{
The term 'respect for diversity' has gained prominence in many policy and curricular \\ developments aimed at promoting reconciliation and pluralism. To explore the \\ understandings of 'respect for diversity' held by children in a society that has both \\ emerged from conflict and is increasingly multicultural, 15 group interviews were \\ conducted with 7-11 year-old children in Northern Ireland. The behavioural aspects of \\ respect for diversity articulated by the children were identified as: attention; offering \\ time; equality of treatment; and acts of solidarity. Affective motivations for these actions \\ were empathy and the pursuit of friendship; cognitive motivations were: a moral norm of \\ inclusion; curiosity; internalised human rights principles; and egalitarianism (a belief that \\ all persons are equal in fundamental worth or value). Findings are discussed in relation to \\ theories of children's prejudice development and moral development, and implications \\ for the teaching and promotion of respect for diversity as part of peace education \\ programmes are considered.
}

Keywords: diversity; respect; intergroup relations; middle childhood; Northern Ireland

\section{The interdisciplinary study of respect for diversity}

Many concepts across several fields of study have been linked to respect for diversity, which highlights the vagueness and potential for confusion around the term. In political philosophy, Kant's (1788/2002) individualistic understanding of respect links the concept with notions of equality (equality defined as an appreciation of the inherent dignity of all persons); John Stuart Mill (1861/1979) has linked respect with autonomy and the freedom of all persons. Fraser (1997) outlines a more group-based notion of respect, arguing that recognition, in the 
form of revaluing group identities and cultural products and transforming societal patterns of communication, is the means to reversing cultural injustice in a society where groups have been marginalised and disrespected in cultural representations and in everyday life.

Ethnographic studies from sociology and social anthropology have also investigated the foundations of respectful interpersonal behaviour. Lawrence-Lightfoot $(2009,222)$ found that respect for others presents as an 'empathic connection'; Bolin $(2006,169)$ found that ‘respectful behaviour translates into cooperation, compassion, and responsibility', with reciprocity at the foundation of relations. In the field of conflict resolution, Ury $(1999,127)$ has stated that tolerance is the action or 'work' of respect: 'tolerance is not just agreeing with one another...but rather showing respect for the essential humanity in every person’. For Gibson (2004), respect is a condition that needs to be present for reconciliation to occur.

Furthermore, the link between respect and equality relates it to social psychological research on prosocial behaviours, values, empathy and perspective-taking (and their development), since believing in the equal worth of and consideration for all persons may promote empathy or perspective taking (see Lalljee, Laham, and Tam 2007; Findlay, Girardi, and Coplan 2006; Hoffman 1987). Most frequently, respect is viewed as the opposite of prejudice (see Allport, 1954/1979), especially in literature on the development of prejudice in children (see Carter and Rice 1997; Nesdale and Flesser 2001; Aboud 2005). For example, according to social identity development theory (see Nesdale 2004), children’s transition from ethnic preference to prejudice depends on three factors: whether a child acquires a sense of ethnic constancy (the understanding that ethnic group membership is unchangeable); the acquisition of social-cognitive skills (including the ability to decentre oneself, empathise with another, and engage in higher-level moral reasoning); and social identity processes (including adopting a negative outgroup attitude that prevails in their ingroup as their own). 
Respect is also mentioned in cognitive theories of children's moral development - in Piaget’s (1932/1965) view, only adult-child relationships that are characterised by mutual respect rather than coercion will lead to a construction of a personal feeling within the child that moral rules are necessary. Kohlberg (1971), like Kant, saw respect for the dignity of all persons as one of the self-chosen ethical principles that are defined by a person at the sixth and final stage of their moral development. This is a principle that is defined as universal; it is valid regardless of the group holding the principle or a person's identification with the group. According to Goodman (2009), mutual respect as a moral code develops because a child begins to learn that there are legitimate multiple viewpoints to issues, that rules are created through mutual agreement, and that breaking those mutually agreed rules would violate the group norms. This cognitive explanation is built upon by Barbarin and Odom's (2009) model of the development of social acceptance and respect for diversity in children. They see this cognitive development, together with the social and moral development of perspective taking, empathy, and conscience, leading to the development of specific prosocial attitudes and behaviours that constitute respect for diversity.

The interrelated nature of the aforementioned concepts and behaviours with respect demonstrates the integral value of respect as a foundation for harmonious societies and it illustrates why the promotion of respect for cultural diversity is often viewed as an objective of peace education programmes. The present research therefore sought to uncover deeper understandings of the concept of respect; not just what it means in reference to negative concepts such as prejudice or racism, but what it stands for in its own right. The elusiveness of the concept has left it open to interpretation, which potentially dilutes the effectiveness of programmes that aim to promote it. The focus was the point of view of children: despite the above-mentioned body of work on children and the development of their intergroup attitudes, few studies have focused explicitly on children's conceptualisations of 'positive' concepts 
such as respect or tolerance (see Chunmei, Zongkui, and Hsueh 2005; Witenberg 2007). Northern Ireland provided a fitting context for this exploratory study for several reasons. Firstly, the revised primary school curriculum in Northern Ireland (see DENI, 2007) reflects the perceived importance of respect for diversity in children's education, where 'Personal Development \& Mutual Understanding’ (with respect for diversity falling under this heading) has been formalised as a key area of learning in the curriculum. Secondly, educational policy since the Good Friday Agreement of 1998 demonstrates a renewed commitment to inclusiveness in classrooms across Northern Ireland. Schools in Northern Ireland are required to promote pluralism in education and 'a culture of tolerance' (Department of Education Northern Ireland (DENI), 1998). Thirdly, Northern Ireland is an increasingly multicultural society. The proportion of residents from minority ethnic groups has doubled over the period between 2001 and 2011 (see NISRA 2011). In the four years prior to this study, the number of children in Northern Irish primary schools who were not born in Northern Ireland or who did not have English as a first language rose steadily, nearly doubling from 2636 in the 2006/2007 school year to 5130 children in the 2009/2010 school year, representing $3.1 \%$ of all primary enrolments (DENI 2015). Although these numbers are relatively small, it could be argued that children born in Northern Ireland who started primary school since 2006 are more likely to have met a child who was not born in Northern Ireland or who does not have English as a first language than children who started school in the early 2000s. Furthermore, given the established but relatively unsettled nature of the peace process in Northern Ireland (see Nolan 2014, for the most recent Peace Monitoring Report), it would be unwise to assume that the new generation have had no exposure to violence or sectarianism; the society continues to experience deep sectarian division along traditional Protestant/Unionist/Loyalist and Catholic/Nationalist/Republican lines (see ARK 2015; Belfast Interface Project 2012; Magill, Smith, and Hamber 2010). No studies though have yet focused explicitly on how children 
perceive the concept of respect for diversity, particularly in a society such as Northern Ireland that has been through such trauma and which still struggles with aspects of its peace process. Such a study begins to address an important gap in evidence-based policy and practice, since in the meantime educators have been required to promote the concept of respect for diversity without knowing how children view it. Peace education approaches may be missing important topics or bypassing opportunities for learning that could promote respect for diversity in a more accessible way to children. Understanding children’s conceptualisations could therefore facilitate the way respect is taught within classrooms by highlighting the elements of respect for diversity that children can relate to; this in turn has the potential for further increasing the impact of educational interventions that seek to increase respect.

\section{Methodology}

\section{Research design}

In line with its aims, this study employed a qualitative methodology and a rights-based approach, involving group interviews with children in their schools. Given the lack of knowledge around children's conceptualisations of respect and the need to garner and investigate this from a child's perspective, this research design was deemed appropriate. The UNA Qualitative Methods Learning Group (2010), a group of academics from international universities, have identified an overall lack of qualitiative studies in the field of research involving children and issues of race and ethnicity, arguing that an over-reliance on 'forcedchoice' quantitative studies has resulted in over-generalised findings that fail to reflect the social contexts of children's lives and the nuances of their understandings. The UNA group has also conducted a review of studies that have used qualitative methods to research topics around race and ethnicity with children. They found that particularly useful techniques within semi-structured interviews (in research designs that regard the child as an active participant in 
an interview and not a passive responder) were creative, 'projective' techniques (UNA 2010, 16). This includes the creation of videos, drawings, photographs, using toys and dolls, and the use of stories and scenarios. These techniques, they argue, encourage children to share their ideas about hypothetical or simulated situations. They may also encourage children to share information about their experiences and understandings that they may not have thought about or shared if questioned directly. Furthermore, because they are likely to stimulate the children’s interest, they can make one-to-one or group interviews more enjoyable and build rapport with the researcher.

Since stories and case vignettes have been successfully employed in studies with similar designs and research questions to this study, such as those by MacNaughton (2001) on children’s constructions of 'race’, Davis, MacNaughton and Smith’s study (2009) on children’s understandings of 'whiteness', and Verkuyten, Weesie, and Eijberts’ work (2010) on young people's perceptions of peer victimisation, it was decided that the same projective technique would be used in the group interviews with children here, whereby scenarios relating to respect for diversity would provide a stimulus followed by other semi-structured questions to build on their responses. School and parental consent and children's assent was obtained, and data collection took place between February 2010 and September 2010.

\section{Participants}

Fifteen group interviews (involving 145 children in total) were conducted with children in their schools. Children were recruited through seven primary schools in rural and urban areas of Northern Ireland which, using local government data (NISRA 2010), were identified as areas of high and low concentrations of people from ethnic minorities. The purposive sample included two Catholic-Maintained schools, two state-controlled schools (which are predominantly Protestant), and three 'Integrated’ schools (Integrated schools seek to achieve 
a 40:40 balance in pupil admissions between Catholics and Protestants). In each school, pupils from Year 4 (7-8 years old) and Year 7 (10-11years old) were included in the sample. This is because these year groups were at the end of their respective 'Key Stages' at primary school (Key Stage 1 includes the curriculum for Years 3 and 4, and Key Stage 2 includes the curriculum for Years 5, 6 and 7). This provided a clear benchmark in terms of what children would have been taught about respect for diversity under the 'Personal Development and Mutual Understanding' (PDMU) area of the curriculum (see CCEA 2007, for the content of this curriculum). Furthermore, according to sociocognitve theory (Aboud 1988) and social identity development theory (Nesdale 2004), 7-year-old children may hold markedly more negative attitudes towards outgroups than older children, which was a second reason for discussing respect for diversity with the two age groups separately. It was not anticipated that one of these groups would show 'better' understandings of respect for diversity; only that they may be qualitatively different understandings, and to maximise the range of views that children had.

\section{Procedure}

The group interviews lasted for approximately one hour and explored the children's understandings of 'respect' as well as reasons why they may or may not respect members of other groups. To overcome potential difficulties regarding power, the first ten minutes of each group discussion was spent on an icebreaker activity (the tangled web ${ }^{1}$ activity, to encourage children to listen to each other and to demonstrate that everyone has a different viewpoint) and the group interview was introduced as researcher's 'homework' with which the children might be able to help. The emphasis was on the children as the bearers of knowledge, and the researcher as the 'unknower'. This was followed by a brainstorming session on what they thought respect was and the affective, behavioural and cognitive aspects 
of respect (questions included: Who do you show respect to?; Why would you show respect to someone? How would you show respect? When you are respected, how does it feel?). Four case vignettes followed the initial brainstorming. The stories in the vignettes dealt with issues of interpersonal and intergroup respect and prejudice between children of different religious and ethnic backgrounds and were created according to the guidelines of Barter and Renold (1999). The children were asked what they would or would not do/feel/say if they were the characters in the stories, in order to draw out what they understood by being respectful of diversity.

When researching a concept, behaviour, attitude or issue that is deemed socially desirable or normative, there is a danger that participants will answer in ways that are closer to what they think are desirable or normative responses rather than what they really think. This is especially true when researching with children in a school context, and when the topic at hand is actively promoted in their schools. However, the children did not always give uncontroversial answers or act in socially acceptable ways, which suggests that they felt comfortable enough with the research procedure to state their honest opinions. For example, several children expressed the opinion that 'Catholics and Protestants just don't get along', to use one quote; another child recited a racist rhyme along with a racist gesture, which she said she would not have done if someone from the target racial group had been in the room.

While there was a possibility that participating children who have experienced discrimination or prejudice in the past could have been reminded of such negative experiences during the group interviews, the risk was minimised as no child was asked to directly talk about his or her personal experiences - the fictional case vignettes were the main method used to prompt discussion. Children sometimes discussed times when they had witnessed prejudice and, in one case, a child discussed how he felt he had been treated 
differently at times because he had been born outside of Northern Ireland, but this information was offered freely, and was not asked for directly by the researcher.

Lastly, children were asked to draw a picture of 'respect' to give them an opportunity to bring up anything else they wanted to explain or describe about respect. This worked especially well for quieter children in the group in helping them find their voice - they concentrated on their pictures, then took time to explain what the pictures were about. The drawings were thus used as a prompt for further discussion, rather than data in their own right.

The group interviews were conducted in a room away from the rest of the children's classes and teachers (although a classroom assistant was present when children with special needs took part). The group interviews were recorded and a denaturalised style of transcription was conducted. The data were analysed using the thematic analysis approach (Braun and Clarke 2006) with NVivo ${ }^{\circledR} 8.0$ software - initial notes on the transcriptions were transformed into emerging themes or concepts and recorded as either free nodes or tree nodes in NVivo ${ }^{\circledR}$. The emerging themes were then reviewed and checked against quotes from the data set, generating an initial thematic map which evolved to tell the overall story of the data.

\section{Results: Mapping Children's Understandings of Respect for Diversity}

Figure 1 shows a map of the behavioural, cognitive and affective aspects of respect for diversity that were identified from the children's data. The lines link the internal cognitive and affective antecedents or motivations behind respect to their associated respectful behaviours. These facets of respect are also associated with more abstract motivations listed on the left side of the figure. Contextual factors were found to affect the type of behaviour that a child associates with respect, as well as the reasons why they would give respect. This is factored in at the bottom of the map. 
[Insert Figure 1 here]

Figure 1. Map of children's understandings of respect for diversity

Each of the behavioural elements of respect identified in the model are presented as thematic sub-headings in the results section, but because the motivations for respect were interconnected and overlapping, they are discussed as they relate to each behaviour they were associated with.

\section{Attention}

Attentiveness as a behavioural element of respect for diversity was motivated in part by a genuine curiosity about other traditions and cultures. This included asking questions to learn about the other group, listening to them and acknowledging their difference. When asked how they would show respect to a new boy in a the class who had emigrated to Northern Ireland from China, children from all year groups and educational sectors believed that by asking a person about their behaviours and attitudes as individuals and about the characteristics of his or her ingroup, they were showing respect to that person:
A: Talk about his country and what he would do there
B: Ask what would he do normally during the day
C: Ask him what he likes (Year 4, Rural, Controlled)

For some younger children, this even extended to trying to adapt to and learn from the 'new' social norms and practices: 

A: He might not want lunch because in his old school they might not eat lunch
B: Maybe help him to talk English, and he could help you to talk Chinese (Year 4, Urban, Catholic-Maintained)

However, in line with Aboud's (1988) sociocognitive theory, some of the older children in the sample could differentiate between individuals and the community or group of which they were members. Even if they did not respect their group, they stated that it was still possible to respect the person as an individual, since the individual may have characteristics that are different from the group characteristics:

\author{
I: Can you respect a person, but not the group or community they belong to? \\ Yeah \\ I: How is it that you can think about them differently? \\ By like, taking them apart from the team as well as everybody else, and focusing more \\ on the person than the team, and you can have more respect for them. (Year 7, Urban, \\ Controlled)
}

As shown in Figure 1, another explanation for asking questions and learning about others was that there was a rights-based reason to do so. Mirroring the language that is used in the Northern Irish PDMU curriculum around intergroup similarities and differences (see CCEA 2007), respect was viewed as something due to everyone as a matter of them being human, no matter which nationality or religion they belonged to:

I: Why do we show respect to people who are different from us?

A: Because we are all the same 
B: People learn the same things only in different words (Year 4, Urban, CatholicMaintained)

Some children who were at Integrated schools argued that people who were different also had a human right to be acknowledged and valued equally:

I: Why do you think it's important to understand people's differences?
A: They have rights as well
B: Like about their right to religion
C: You have a right to your own religion (Year 7, Rural, Integrated)

This is very similar to Fraser's (1997) notion of recognition: the principle of not only acknowledging others' difference, but seeing the value in their difference and an inherent value in being inclusive:
A: It's better when you are all different, because if we were all the same it would be dull and boring
B: If everyone was the same it would be dull and it wouldn't be fun (Year 4 and Year 7, Rural, Integrated)

While one should acknowledge differences, the children thought that pointing out a person's difference to another in an offensive way is unacceptable:

I remember in P3 when we were having dinner, I was sitting beside a boy in our class who has something wrong with his tongue and he was trying to tell me something and 
this wee girl from P3 walked past us and said ‘he can’t talk properly’ (Year 4, Urban, Catholic-Maintained)

A second if not so altruistic motivation to be attentive to people was to gain friends for oneself - the children believed that by listening and learning about others you were more likely to find people with whom you wanted to be friends. You were therefore less likely to be lonely, and other people may view you as a nice person to be around as well and therefore want to be friends with you:

At lunchtime you could invite [the new boy] to play and ask questions to see if you have anything in common like maybe afterschool he could come to your house and you could do whatever you have in common. (Year 4, Urban, Catholic-Maintained)

Thirdly, empathy again was at play - it was believed that paying people genuine attention would ease the nervousness and discomfort of someone who was new to a place, and it would make them feel more comfortable:

I: Why did your teachers ask you to [show the new boy in the class respect?]

A: Because he’s from a different country and has a different skin colour, they're just saying that to make him fit in and feel welcome

B: The teacher might not want him to feel left out and have no friends. (Year 4, Urban, Catholic-Maintained)

This theme illustrates more nuanced differences in understandings based on children's ages and their school context, and also it reflects an aspect of respect with which the children 
would be very familiar, as 'examining and exploring difference' is an explicit learning intention in the Northern Irish school curriculum (see DENI 2007).

\section{Offering Time}

The second main action of respect was spending time with others, particularly through play. For children of all ages and from all school locations and sectors, play was regarded as a universal mechanism that bonds everyone. Playing with someone who was new, sharing your things and offering practical help, such as taking the time to teach the social norms of one's own ingroup, came under this action. This included explaining the rules of the classroom to a new child and what they were expected to do, showing them how to play games and so on, in order to help them 'fit in'. It was also seen to be the right thing to do on a moral level children had internalised a moral norm of inclusion:

I: Why do we show respect to people who are different from us?
A: It wouldn't be right to just leave them out or anything
B: If someone's lonely and they have no one to play with, you can go over and say 'play in our game' (Year 4, Urban, Catholic-Maintained)

Playing with others was closely related to friendship. Offering friendship to those who were different, not excluding people, encouraging others to make friends with the 'different' or new person, and the strength of friendship bonds were emphasised in terms of showing respect:

I: How would you make [the new pupil from China] feel welcome?
A: Be friendly to them
B: Help him make new friends 
Because time was viewed as valuable, ignoring and not spending time with someone who was regarded as disrespectful was seen as a way of silently condemning disrespectful behaviour without the risk of deepening the hurt that is caused to others or becoming the target of disrespect yourself. Nonetheless, children stated that they would make special efforts to share their time with someone they viewed as disrespectful if there seemed to be an emotional or affective reason for their disrespectful behaviour, such as loneliness, jealousy, shyness, or even their own feelings of 'difference' in a certain context - again, they were able to empathise with a child who is left out. If that was indeed the case, children stated that they would use a range of strategies to help the person - they might confront the problem, use humour or play:

I: Why do you think Claire wouldn't have wanted to talk to you??

B: She could have got disrespected from them already and be very angry, so she takes it out on someone else

A: She looks sad so maybe someone has bullied her and she wants to take it out on them

C: I would feel happy just to sit beside her and talk to her and be like, listen to my music or something, try to help her out

A: You don't know what everybody's like....you might be like hard on the outside but inside you're like soft. All the other people, you probably think they're the exact same as you but in the inside they could probably...feel like crying too (Year 7, Rural, CatholicMaintained)

Offering practical help was also done out of empathy, as it could ease a 'newcomer' person's discomfort. Unlike the reasons for offering play such as wanting to gain a friend or ease their 
own loneliness, practical help was offered because of the more altruistic motivation of simply being helpful and easing any unfamiliarity that others may feel. This was particularly important for the Year 4 children - it was mentioned in all of their group interviews, but only in one of the Year 7 groups. This may be due to the emphasis on play-as-active-learning in early years and Key Stage 1 education in Northern Ireland.

In sum, taking the time to show others the ways that they can 'fit in', teaching them the social norms of a new environment, or sharing ingroup beliefs and insider knowledge were key ways to show respect.

\section{Equality of Treatment}

The third main action of respect was simply treating others equally (in terms of treating others the way one wishes to be treated too) and following the accepted social norms of 'proper' conduct when interacting with another person. The children emphasised regularly the importance of having good manners and being 'nice'. This behaviour had two common antecedents - a belief in egalitarianism, and an internalised moral norm of including others. The tone and delivery of what is said also mattered to children, as that was considered part of how a person perceives whether a message is respectful or not, which in turn decides whether the interaction becomes respectful or not. Even when people show curiosity about another culture, questions can be asked in a sarcastic or 'bad' way that undermines it as an act of respect:

A: I’m from Holland, and sometimes people treat me differently, but in a good way sometimes. Like they treat me more popular than other people, but sometimes people make fun of me because I’m from Holland.

I: Do they ask you any questions about what it was like over there?

A: Yeah, sometimes it's in a bad way as well. (Year 7, Urban, Catholic-Maintained) 
Body language and language use was very important here - children emphasised always looking someone in the eye when talking, opening doors for people and so on. This was not just for adults - it was expected behaviour towards everyone, but particularly as it would help outgroup members or 'newcomers' feel more comfortable:

I: How would you show respect for another person?
A: Treat people the way you want them to treat you
B: Be kind to him
C: Be nice to each other
D: Not showing respect is being cheeky
E: Before you say something cheeky to someone, think how would you like it if someone else says that to you (Year 4, Urban, Catholic-Maintained)

The language used by Child $\mathrm{E}$ in the excerpt above indicates that the reasoning children gave for conducting themselves in this way also stemmed from empathy - it was deemed important to consider others’ thoughts and feelings before you speak or act.

\section{Acts of Solidarity}

Carrying out acts of solidarity with a person who was regarded as 'new' to a context or who was being bullied for their difference, and defiance against a prejudiced person was the fourth and final behavioural aspect of respect for diversity articulated by the children. This included 'telling' authorities such as a teacher or a parent about the disrespectful person and what they were doing, not acquiescing with behaviour they viewed as picking on someone because of their difference, and also excluding themselves from an activity if someone else was being deliberately left out: 
A: Yeah I'm friends with a girl called Alicia and she has autism, she's from St John's school.

I: Does she ever have any problems with people respecting her?

A: Sometimes, people would say like look at you you're different and you have to stand up for her. (Year 4, Urban, Catholic-Maintained)

Many examples of this action were articulated in response to the case vignettes, especially the Year 4 case vignette about a boy called Ben who did not want his friend Joe to bring his neighbour to his birthday party, as Joe’s neighbour goes to a different school and attends a different church to them:

\section{I: What would you say to Ben in that situation?}

A: If you don’t accept me then you don’t accept my friend

B: I wouldn't say anything, I would just say 'I'm not going to the party anymore'

C: I would just say, I’m going to bring him anyway

D: I would say to my friend, sorry, you can’t go to party and I'm not going to go either.

And I would play with him on the street then (Year 4, Urban, Controlled)

Two main reasons were given for acting this way. Firstly, the children had a strong sense of egalitarianism - there was a belief that all persons are equal in fundamental worth or value. As such, discriminating on the basis of arbitrary characteristics was seen to erode a person's dignity, and this prompted their act of solidarity. Secondly, the latter quote also hints that children felt a sense of empathy with the excluded person - they understood that it would make that person feel better if they stood shoulder to shoulder with them: 

A: Just don't go to Ben’s party because it wouldn't be fair on Mark
B: It wouldn’t be fair on his friend. Just say sorry I can’t come (Year 4, Rural, Controlled)

\section{I: How do you think Mark would feel?}

A: Just because he’s different from them it doesn't mean he can’t come

B: It would be unfair, I think Mark would feel lonely and think Ben doesn’t like him just because he’s a little bit different (Year 4 and Year 7, Rural, Integrated)

It is clear from this theme that children viewed respect for diversity as something that necessitates activism and advocacy on the part of those who face difficulties due to their difference. Holding a justice principle of fairness or having emotional competencies such as empathy motivate this type of action, but having a sense of fairness or being strongly empathic alone is not enough if one is to be truly respectful - respect requires action.

\section{The Importance of Past Personal Experience}

The emphasis that a child placed on one, some or all of the identified four actions of respect and the reasons given for them were however dependent on their past experiences with a group or with an individual - a positive or a negative experience made it easier or harder to show respect. The experiences of children's parents' with a group or an individual was also a significant factor - children recognised that parents can encourage friendships and new experiences with new people, discourage them, or even block friendships if they fear the influence of another child. While this point refers to children from ethnic minorities, it must be emphasised that for many children, diversity to them reflected exactly what they had encountered in their environment - some mentioned people from different countries whom they had met on holiday abroad; for others, diversity referred to a child in school who had 
learning difficulties, or an immigrant family who lived in their village (especially for those children from rural areas).

\section{Abstract Motivations for Showing Respect}

The left side of the model in Figure 1 shows the more abstract reasonings given by children for carrying out the four actions of respect. Firstly, they stated that showing respect would foster understanding and prevent conflict - both interpersonal and intergroup conflict, even 'World War III' as one child put it.

I: Why do you think it is important to respect others?

A: Because respect....the world would just fall apart if there's no respect at all. When we were away in Poland it just showed you how much Hitler didn’t respect the Jews and all B: He didn’t have respect for anybody

C: If there was no respect in the world then there would be a lot more war
A: The world would be on fire!
D: There'd be emergencies, we'd be practically dead
B: The world wouldn't be safe
A: The world would have just ended because of all the fighting! Because nuclear bombs and the weapons are more advanced so it can destroy the world, so it's good to have respect (Year 7, Rural, Catholic-Maintained)

The quote above illustrates that, for some children, respect for diversity had the potential to both keep conflict at bay and help to resolve it.

Lastly, many children explained their reasoning and motivation behind showing respect in terms of the reciprocal nature of respect. They believed that one should show respect because it would be shown in return to you. 


\section{Discussion}

Firstly, the findings showed that 'respect for diversity' as a concept cannot be fully extricated from theories of prejudice development - respect was often viewed in the data as the opposite attitude to religious, racial, homophobic, age or ability-related prejudice. Secondly, it was clear that respect for diversity involves the three elements of attitude identified by Breckler (1984) and Eagly and Chaiken (1998) - it had cognitive, affective, and behavioural aspects. Cognitive elements included the perception of a moral norm of inclusion, curiosity, the internalisation of human rights principles, and the holding of egalitarian values. Affective elements included empathy and the desire to avoid loneliness; and behavioural elements included attentiveness, spending time and playing with others, treating others equally and according to the norms of proper conduct, and acts of solidarity. The findings therefore shed light on the socialisation strategies (to be employed, for example, by parents and teachers) that could result in children not developing a prejudiced attitude. The nurturing of empathy in children is one such tactic. However, nuturing respectful interactions is not just about evoking empathy for excluded others - for any intervention to be truly successful in building respect, avenues must be facilitated for turning empathy into action, as evidenced in the data. This finding implies that, even for young children, educational curricula and programmes aiming to promote positive community relations could explore the idea of solidarity (in the forms of activism or protest) as an empathy-based, respectful action on behalf of others.

A second socialisation strategy must be the nurturing of children's curiosity. The 7-8 year olds (in particular) who took part in this research showed an exceptional level of openness and honesty, and a desire to ask questions about people and groups who were different to them, even in their presence. This inquisitiveness should be encouraged, particularly alongside the teaching of 'proper' conduct (which the children also regarded as 
respectful behaviour), as children could be taught the tools to ask questions in appropriate ways without causing offence. Thirdly, the presence of an internalised moral norm of inclusion and respect was also evident in the children's results, as they continually pointed to an acceptance of difference as a part of life - it was something you 'had to do' because valuing difference was essential for the prevention of conflict. Nuturing a moral norm of inclusion is therefore a third socialisation strategy that could contribute to the absence of prejudiced attitudes in children; indeed, this is something that is viewed as vital for combating prejudiced attitudes in society according to Abrams et al.’s (2009) Theory of Social Mind.

The results also showed that egalitarianism as a justice principle and the core principles of human rights must be appealed to in children if respect for diversity is to transpire. Children advocated equality in terms of treating people by the same set of standards, which sometimes involved appeals to human rights and the linking of equality to notions of reciprocity and empathy by 'treating others the way you want to be treated yourself'. No matter if someone was viewed as disrespectful or offensive (in other words, no matter if others had a low social 'input'), respect could still be shown to all by sharing equally and including everyone in games. This was also seen by children as something that could promote respect for diversity in the future, since the disrespectful children could be 'educated' in perspective-taking. While the adoption of notions of 'fairness' is highlighted in Barbarin and Odim’s (2009) and Hoffman’s (1991) theories on moral development, this is ignored in theories on the development of prejudice in children. Perhaps the additional ingredient of egalitarianism in the understanding of 'respect for diversity' is the divergent point in the road at which it is no longer simply an attitude that is the opposite of prejudice, but where it becomes something more akin to a moral value which generates specific behaviours. 
As Oppenheimer (2010) argues, developmental issues and emotional reactions to reality are important to understand if the goals of peace education are to be realised, and the findings here support aspects of theories of moral development that are relevant to peace education. Firstly, it was clear from the data that empathic responses were a key motivation for having and showing respect for diversity. This feeds into the theoretical debate over the role of cognition and affect in morality - cognitive developmental theorists such as Piaget and Kohlberg would claim that the cognitive capacity for taking the perspective of others is central to the quality of a prosocial behaviour, such as the behaviours that were identified in the study as respectful. However, authors such as Barbarin and Odom (2009), Eisenberg (1986), and Hoffman (1987), would claim that empathy, defined as an affective response to the understanding of others' emotional states, can stimulate moral reasoning and cognitions and is a direct motivator for prosocial behaviour. Looking at the data, it was the anticipation of particular emotions in other individuals that led to the articulation of respectful behavioural intentions. It also appears from this study that empathy was induced by imagining the circumstances of characters in the particular stories discussed during the group interviews. In this way, the data here seem to represent a middle ground between the two theoretical positions: taking the perspective of the character was the cognitive ability or mechanism that enabled a child to have an emotional response, or empathy, which in turn prompted the respectful behavioural intention. The study therefore lends more support to the link between empathy and ethnic attitudes (see Nesdale et al. 2005), and to the research suggesting that attempts to enhance children's empathy may be useful in efforts to increase children’s liking for ethnic outgroup members (see Aboud and Levy 2000). Perhaps, as Aboud and Brown (2010) argue, more experimental studies are needed to identify the necessary components of interventions that arouse emotions (empathy) in response to witnessing discrimination. Some of the children also had difficulty disentangling the concepts 
of respect for diversity and liking for others. This may indicate that in the teaching of respect for diversity, more emphasis may also need to be placed on the recognition of group-based rights that are apart from an individual's personal characteristics (that is, those which would influence whether they are 'liked' as a friend or not).

The results also illuminate age differences in moral reasoning, which is an important consideration for the design of age-appropriate peace education programmes. While the main themes underpinning children's understandings of respect for diversity were the same for both younger and older children, there were some nuances that separated them. These nuances represented the increasing focus by older children on individual psychologies and characteristics, and the social-emotional events that occur within and between people. This could be seen as a reflection of the conventional stage of moral reasoning that some of them had reached (using Kohlberg's (1976) definition), or, in Piaget's terms, the socialisation of intelligence (1932/1965) - the realisation that people can have differing interpretations and perspectives on the same events and that their needs can sometimes trump one’s own individual desires. For example, it was older children who referred to the fact that individual group members may have traits that do not conform to group stereotypes, and they referred to historical divisions between cultures and countries or different parental attitudes and experiences that may impact on the way a child behaves and feels towards a group. Older children also displayed more flexibility around rules - another indication that they had reached conventional stages of morality. While they were more willing than younger children to call on authority to help another child, they were also more willing than younger children to break a rule if they thought it was unfair and disrespectful. Some of the children (but especially younger children) gave motivations for respectful behaviour that reflected Kohlberg's pre-conventional stage of moral reasoning (1976), in that they acted in selfinterest, to earn more friends - a reciprocal form of morality. 
. Although the study lends support to the importance of middle childhood as a period during which children's categorisation of others becomes more complex, the children in this study dealt with respect for diversity mainly at the interpersonal level (like Kant and Mill’s conceptions), as opposed to the intergroup level. Behaviour towards others who are different was based mainly on a sense of empathy toward that individual, and an acknowledgement of their difference and their human rights. When group categories were discussed, it was children from Catholic-Maintained schools and Integrated schools who used the group labels of 'Catholic' and 'Protestant' in talk about respecting diversity. These groupings were not mentioned in the group discussions with children from state-controlled schools - when they spoke about respecting diversity, they only referred to other types of difference, including disability and the cultural differences between people from different countries. Although only suggestive, these findings could be reflective of the varying salience of these group labels in different school sectors, and it reflects the need for teachers to feel supported and able to handle potentially difficult discussions about community relations in Northern Ireland. These findings may also imply that lessons or programmes that aim to promote respect for diversity should be focused more on the connections between a person's individual identity and their group identity. This is particularly relevant for other societies emerging from conflict and that are increasingly diverse. The context of Northern Ireland has thus provided a rich starting point for the development of a nuanced theoretical understanding of respect for diversity.

Funding Acknowledgement: Stephanie Burns received a $\mathrm{PhD}$ studentship from the Improving Children’s Lives interdisciplinary research initiative at Queen’s University Belfast, which provided the funding to carry out this research. 
Acknowledgements: The authors would like to thank the pupils and schools involved in this study for allowing us to conduct the research. Thanks are due also to Dr Chelsea Marshall and the anonymous referees of an earlier draft of this paper for their insightful comments.

\section{References}

Aboud, F. 1988. Children and Prejudice. Oxford: Basil Blackwell.

Aboud, F. 2005. "Prejudice in Childhood and Adolescence”. In On the Nature of Prejudice: Fifty Years After Allport, edited by J. Dovidio, P. Glick, and L. A. Budman, 310-326. Oxford: Blackwell.

Aboud, F., and Brown, C. 2010. Positive and Negative Intergroup Contact among Children and its Effects on Attitudes: UNA Working Paper 2. Belfast: UNA.

Aboud, F., and Levy, S. 2000. "Interventions to Reduce Prejudice and Discrimination in Children and Adolescents.” In Reducing Prejudice and Discrimination. The Claremont Symposium on Applied Social Psychology, edited by S. Oskamp, 269-293. Mahwah, NJ: Erlbaum Associates.

Abrams, D., Rutland, A., Pelletier, J., and Ferrell, J. 2009. “Children’s Group Nous: Understanding and Applying Peer Exclusion Within and Between Groups.” Child Development 80 (1): 224-243.

Access Research Knowledge (ARK). 2015. "Young Life and Times Survey” [Community Relations Module]. Accessed August 252016. http://www.ark.ac.uk/nilt/2015/Community_Relations/

Allport, G. 1954/1979. The Nature of Prejudice (25th anniversary ed.). Reading, MA: Addison-Wesley.

Barbarin, O., and Odom, E. 2009. “Promoting Social Acceptance and Respect for Cultural Diversity in Young Children. In Handbook of Child Development and Early 
Education: Research to Practice, edited by O. A. Barbarin and B. H. Wasik, 247-265. London: Guildford Press.

Barter, C., and Renold, E. 1999. “The Use of Vignettes in Qualitative Research. Social Research Update, Issue 25.” Surrey: University of Surrey. Accessed August 252016. http://sru.soc.surrey.ac.uk/SRU25.html

Belfast Interface Project. 2012. Belfast Interfaces: Security Barriers and Defensive Use of Space. Belfast: Belfast Interface Project.

Bolin, I. 2006. Growing up in a Culture of Respect: Child Rearing in Highland Peru. Austin, TX: University of Texas Press.

Braun, V., and Clarke, V. 2006. “Using Thematic Analysis in Psychology.” Qualitative Research in Psychology 3 (2): 77-101.

Breckler, S. 1984. "Empirical Validation of Affect, Behavior and Cognition as Distinct Components of Attitude.” Journal of Personality and Social Psychology 47 (6): 11911205.

Carter, C., and Rice, L. 1997. “Acquisition and Manifestation of Prejudice in Children.” Journal of Multicultural Counseling and Development 25 (3): 185-195.

Chunmei, Z., Zongkui, Z., and Hsueh, Y. 2005. "The Conception of Respect and its Development in Childhood.” Psychological Science (China) 28 (2): 337-341.

Council for the Curriculum, Examinations and Assessment (CCEA). 2007. "Personal Development and Mutual Understanding for Key Stages 1 \& 2.” Belfast: PMB Publications. Accessed August 252016.

http://ccea.org.uk/curriculum/key_stage_1_2/areas_learning/personal_development_ mutual_understanding

Davis, K., MacNaughton, G., and Smith, K. 2009. “The dynamics of whiteness: children locating within/without.” In 'Race’ and Early Childhood Education: An International 
Approach to Identity, Politics and Pedagogy. Edited by G. MacNaughton and K. Davis, 46-66. New York: Palgrave Macmillan.

Department of Education for Northern Ireland (DENI). 1998. Towards a Culture of Tolerance: Education for Diversity. Bangor: DENI.

Department of Education for Northern Ireland (DENI). 2007. The Education (Curriculum Minimum Content) Order (Northern Ireland) 2007. Bangor: DENI.

Department of Education for Northern Ireland (DENI). (2015). "School enrolments Northern Ireland Summary Data.” Bangor: DENI. Accessed August 252016. https://www.education-ni.gov.uk/publications/school-enrolments-northern-irelandsummary-data

Eagly, A., and Chaiken, S. 1998. Attitude Structure and Function. In The Handbook of Social Psychology. $4^{\text {th }}$ ed. Edited by D. Gilbert, S. Fiske and G. Lindzey, 269-322. New York: McGraw-Hill.

Eisenberg, N. 1986. Altruistic Emotion, Cognition, and Behavior. Hillsdale: Erlbaum.

Findlay, L., Girardi, A., and Coplan, R. 2006. "Links Between Empathy, Social Behaviour, and Social Understanding in Early Childhood.” Early Childhood Research Quarterly 21 (3): 347-359.

Fraser, N. 1997. Justice Interruptus. London: Routledge.

Gibson, J. 2004. “Does Truth Lead to Reconciliation? Testing the Causal Assumptions of the South African Truth and Reconciliation Process.” American Journal of Political Science 48 (2): 201-217.

Goodman, J. 2009. “Respect-due and Respect-earned: Negotiating Student-Teacher Relationships.” Ethics and Education 4 (1), 3-17. 
Hoffman, M. 1987. “The Contribution of Empathy to Justice and Moral Judgement.” In Children's Understanding of Emotion, edited by C. Saarni and P. L. Harris, 47-80. Cambridge: Cambridge University Press.

Hoffman, M. 1991. “Empathy, Social Cognition, and Moral Action.” In Handbook of Moral Behaviour and Development, edited by W. M. Kurtines and J. L. Gewirtz, 275-301. Hillsdale: Lawrence Erlbaum.

Kant, I. 1788/2002. Critique of practical reason. Trans. W.S. Pluhar. Indianapolis, IN: Hackett.

Kohlberg, L. 1971. “Stages of Moral Development.” In Moral Education, edited by C. Beck, B. Crittenden, and E. Sullivan, 23-92. Toronto: University of Toronto Press.

Kohlberg, L. 1976. “Moral Stages and Moralization: The Cognitive-Developmental Approach.” In Moral Development and Behaviour: Theory, Research and Social Issues, edited by T. Lickona, 31-53. New York: Holt.

Lalljee, M., Laham, S., and Tam, T. 2007. “Unconditional Respect for Persons: A Social Psychological Analysis.” Gruppendynamik und Organisationsberatung 38 (4): 451464.

Lawrence-Lightfoot, S. 1999. Respect: An Exploration. Reading, MA: Perseus Books. MacNaughton, G. 2001. “"Blushes and birthday parties": Telling silences in young children's constructions of 'race'.” Australian Research in Early Childhood Education 8 (1): 41 51.

Magill, C., Smith, A., and Hamber, B. 2010. The Role of Education in Reconciliation. Coleraine: UNESCO Centre, University of Ulster.

Mill, J. S. 1861/1979. Utilitarianism. Indianapolis, IN: Hackett. 
Nesdale, D. 2004. “Social Identity Processes and Children’s Ethnic Prejudice.” In The Development of the Social Self. Edited by M. Bennett and F. Sani, 219-245. Hove: Psychology Press.

Nesdale, D., and Flesser, D. 2001. “Social Identity and the Development of Children’s Group Attitudes.” Child Development 72 (2): 506-517.

Nesdale, D., Maass, A., Durkin, K., and Griffiths, J. 2005. “Group Norms, Threat, and Children’s Racial Prejudice.” Child Development 76 (3): 652 - 663.

Nolan, P. (2014). Northern Ireland Peace Monitoring Report: Number Three. Belfast: Community Relations Council.

Northern Ireland Statistics and Research Agency (NISRA). 2010. “International NetMigration (2008-9): NISRA Estimates. (Excel).” Accessed August 252016. http://www.nisra.gov.uk/demography/default.asp18.htm

Northern Ireland Statistics and Research Agency (NISRA). 2011. Census 2011: Key Statistics for Northern Ireland. Belfast: NISRA.

Oppenheimer, L. 2010. “Contributions of Developmental Psychology to Peace Education.” In Handbook on Peace Education, edited by G. Salomon \& E. Cairns, 103-120. New York: Psychology Press.

Piaget, J. 1932/1965. The Moral Judgement of the Child. New York: Free Press.

UNA Qualitative Methods Learning Group. 2010. “Researching 'Race’ and Ethnicity with Children in the Field: A Critical Appraisal of Qualitative Research Approaches, Methods and Techniques, UNA Working Paper 4.” Belfast: UNA. Accessed August 25 2016. http://www.unaglobal.org/documents/unaworkingpaper4.pdf

Ury, W. 1999. Getting To Peace. New York: The Penguin Group. 
Verkuyten, M., Weesie, J., and Eijberts, M. 2010. “The Evaluation of Perpetrators and Victims of Peer Victimization: An Extended Crossed-Categorization Approach.” European Journal of Social Psychology 41 (3): 324-334.

Witenberg, J. T. 2007. “The Moral Dimension of Children's and Adolescents' Conceptualisation of Tolerance to Human Diversity.” Journal of Moral Education 36 (4): 433-451.

\section{Notes}

1. See http://www.mftrou.com/a-tangled-web-team-building-exercise.html

2. This vignette consisted of: 'On a cross-community school trip, you are paired with Claire, who is from a school which has pupils of a different religion from you. You have been told that after the school trip, you will have to write a page about how Claire's beliefs are similar or different from yours. However, when you meet Claire, she says she doesn't want to talk to people like you, meaning people from your religion.’ 